\title{
Nordiques
}

33 | 2017

La transition des villes nordiques : quelles innovations territoriales en périphérie?

\section{Louis Clerc, La guerre finno-soviétique (novembre 1939-mars 1940)}

Economica, 2015

Julien Neuville

\section{(Q) OpenEdition \\ Journals}

Édition électronique

URL : https://journals.openedition.org/nordiques/3423

ISSN : 2777-8479

Éditeur :

Association Norden, Bibliothèque de Caen la mer

Édition imprimée

Date de publication : 1 mai 2017

Pagination : 141-143

ISBN : 978-2-9544654-9-4

ISSN : $1761-7677$

Référence électronique

Julien Neuville, «Louis Clerc, La guerre finno-soviétique (novembre 1939-mars 1940) », Nordiques [En ligne], 33 | 2017, mis en ligne le 19 janvier 2022, consulté le 02 février 2022. URL : http://

journals.openedition.org/nordiques/3423

Ce document a été généré automatiquement le 2 février 2022

Nordiques 


\title{
Louis Clerc, La guerre finno- soviétique (novembre 1939-
} mars 1940)

Economica, 2015

\author{
Julien Neuville
}

\section{RÉFÉRENCE}

Louis Clerc, La guerre finno-soviétique (novembre 1939-mars 1940), Economica, 2015, 224 pages

1 La guerre d'Hiver est surtout connue pour la résistance inattendue de la Finlande, ce petit pays du Nord de l'Europe, face à son géant voisin, l'URSS. Dans une démonstration claire et très structurée, l'ouvrage de Louis Clerc apporte un complément d'informations nécessaire sur l'émergence et le déroulement de ce conflit, des données finalement peu connues du public francophone.

2 En point de départ, l'auteur place l'émergence de ce conflit dans les coulisses diplomatiques entre Finlandais et Soviétiques durant les années 1938-1939. L'URSS cherche à protéger une de ses grandes villes, Leningrad, et demande à la Finlande de céder du territoire. Au fil des mois, devant le refus du gouvernement finlandais, la guerre apparait comme la seule solution pour Staline.

3 Ensuite, Clerc évoque les préparations de la guerre dans les deux camps. Du côté finlandais, les préparations - renforcement de la ligne Mannerheim, entraînements des réservistes, par exemple - sont faites dans les deux derniers mois. Du côté soviétique, des plans pour une attaque d'envergure sont établis et les soldats, peu préparés pour une guerre dans un rude climat hivernal, sont amassés en grand nombre. À noter que l'URSS commence cette guerre avec l'idée de libérer le peuple finlandais du joug des «Blancs », les vainqueurs de la guerre civile finlandaise en 1917. 
4 Le 30 novembre 1939, la guerre est officiellement déclenchée. Dans des conditions climatiques très difficiles, l'armée soviétique se heurte à une dure résistance de l'armée finlandaise sur tout le long de la frontière commune aux deux pays. Louis Clerc nous explique que cette résistance provient de multiples facteurs : l'armée soviétique utilise des méthodes et des moyens inadaptés dans ces conditions; l'armée finlandaise pratique une guerre défensive et de guérilla adaptée au terrain extrêmement boisé et lui permet de résister avec succès durant la première phase de ce conflit. La présence de la presse internationale en Finlande permet à cette résistance inattendue d'acquérir une visibilité internationale. L'auteur nous rapporte en plus que le pouvoir finlandais s'appuiera particulièrement sur cet évènement pour espérer une aide militaire en provenance des chancelleries occidentales, notamment auprès du gouvernement français et de son chef, Édouard Daladier. Ce dernier soutenait la « cause finlandaise " de manière particulièrement active, mais pour des raisons de politique intérieure avant tout.

5 Entre les deux parties de cette guerre, l'auteur aborde son impact au sein de chacune des deux sociétés. Le contraste est saisissant: d'un côté, les Finlandais, fortement nationalistes, sont unis; de l'autre, les Russes découvrant la réalité crue derrière la propagande de leur État semblent beaucoup plus désabusés. L'auteur traite également le sujet du «tourisme de la guerre » qu'a connu le pays durant ce conflit : des étrangers se rendirent ainsi fréquemment sur les théâtres d'opération dans le but d'avoir des sensations fortes ou pour des raisons humanitaires, plus que pour participer aux combats à la frontière. La seule véritable aide d'envergure proviendra de la Suède, mais de manière officieuse.

6 Après cet interlude, l'ouvrage nous emmène dans la dernière partie de la guerre (février-mars 1940). Cette période montre l'adaptation du pouvoir soviétique à la résistance à travers le changement de son mode opérationnel. En effet, la stratégie soviétique passe d'une guerre offensive, visant à faire une percée rapide, à une guerre de front soutenue par l'artillerie, et qui rappelle à l'auteur la première guerre mondiale. En parallèle, la diplomatie s'est activée pour trouver un règlement du conflit. Si la Finlande hésite au départ, Louis Clerc nous en explique la raison : le gouvernement finlandais espère une intervention franco-anglaise par la Norvège. De son côté, Staline pousse ses troupes - qui comprennent presque un million d'hommes!-, à conquérir un maximum de terrain afin de mettre la pression sur le gouvernement finlandais et de négocier des annexions de territoires plus vastes qu'avant la guerre. Le 13 mars 1940, alors que son armée se trouve au bord de l'effondrement, l'État finlandais accepte finalement les conditions du pouvoir soviétique et un armistice, vécu comme « honteux » par une partie de la population, est conclu. La Finlande est parvenue à préserver son indépendance.

7 La dernière partie de cet ouvrage évoque les souvenirs de cette «guerre qui n'en finit pas » et l'évolution de son image dans la société finlandaise comme russe. Si la symbolique de cette guerre est fortement liée à une certaine idée de la virilité en Finlande et est rentrée dans le langage du quotidien, l'ouvrage nous apprend qu'elle a aussi été utilisée à des fins de politique intérieure et extérieure, comme sous la longue présidence d'Urho Kekkonen. En revanche, côté soviétique, l'existence de ce conflit a longtemps été niée. Malgré un début de remise en cause juste avant et après la chute de l'URSS, la vision du nouveau pouvoir russe, incarnée par Vladimir Poutine, s'aligne sur la propagande soviétique qui, elle, n'a pas à être remise en cause. 
8 La guerre finno-soviétique est un remarquable travail de synthèse sur cette "guerre périphérique " et il place le contexte qui permet de comprendre la suite des évènements. Si la guerre d'Hiver pouvait jusqu'ici paraître mystérieuse au public français, avec cet ouvrage de Louis Clerc, ce n'est plus le cas. À noter qu'il existe une bibliographie détaillée à la fin de l'ouvrage. 